\title{
Inferior Pedicle Breast Reduction for the Management of Gestational Gigantomastia: Literature Review and a Case Presentation
}

\author{
P. Agbenorku1, W.B. Rockwell2, M. Obeng3', J. Akpaloo', 0. Owusu-Danso', \\ P.E. Hoyte-Williams ${ }^{1}$, B. Farhat ${ }^{1}$, E. Turkson ${ }^{1}$, E. Tano ${ }^{1}$, Z. Schumacher ${ }^{1}$, \\ P.K.S. Fiifi-Yankson ${ }^{1}$
}

\begin{abstract}
${ }^{1}$ Division of Plastic \& Reconstructive Surgery, Department of Surgery, School of Medical Sciences, Komfo Anokye Teaching Hospital, Kwame Nkrumah University of Science \& Technology, Kumasi, Ghana

${ }^{2}$ Plastic Surgery Division, University of Utah Health Sciences Center, Salt Lake City, UT, USA

${ }^{3}$ Section of Plastic Surgery, St. Elizabeth Boardman Health Center, University of Pittsburgh School of Medicine, Boardman, $\mathrm{OH}, \mathrm{USA}$

Email: ptkagbenorku@knust.edu.gh, brad.rockwell@hsc.utah.edu, mko317@hotmail.com, jakpaloos@yahoo.com, oheneba111@googlemail.com, paa_ekow@hotmail.com, boutrosfarhat@hotmail.com, edmundkm@yahoo.com, kanot2001@yahoo.com,zalhassan@hotmail.com,pfiifiyankson@gmail.com
\end{abstract}

How to cite this paper: Agbenorku, P., Rockwell, W.B., Obeng, M., Akpaloo, J., Owusu-Danso, O., Hoyte-Williams, P.E., Farhat, B., Turkson, E., Tano, E., Schumacher, Z. and Fiifi-Yankson, P.K.S. (2017) Inferior Pedicle Breast Reduction for the Management of Gestational Gigantomastia: Literature Review and a Case Presentation. Modern Plastic Surgery, 7, 39-49. https://doi.org/10.4236/mps.2017.74005

Received: July 11, 2017

Accepted: October 29, 2017

Published: October 31, 2017

Copyright $\odot 2017$ by authors and Scientific Research Publishing Inc. This work is licensed under the Creative Commons Attribution International License (CC BY 4.0).

http://creativecommons.org/licenses/by/4.0/ (c) (i) Open Access

\begin{abstract}
Background: The actual cause of Gestational gigantomastia ( $\mathrm{Gg}$ ) remains a dilemma. Its treatment has ideally been surgical, employing most commonly the different pedicle techniques in the last decade. Aim: This paper reviews the literature on the management of $\mathrm{Gg}$ using the inferior pedicle technique (IPT) and supports it with a successful case presentation using the IPT. Method: Using the PubMed search engine and Google scholar, literature search was done for $\mathrm{Gg}$ treated with the inferior pedicle reduction method. Published literature from other sources was also included. Data obtained was cleaned and analysed. The inferior pedicle breast reduction technique was employed without any modification in the normal procedure for the case presented. Results: Thirty-one literature addressing Gg and IPT were identified. Most surgeons use this technique with very good outcomes. Our patient confirmed reduced breast mould, firm and adolescent looking breast with no back, shoulder, neck and rib pains. She also experienced with time increased nipple areolar sensation, ability to undertake all tasks with ease and a new sense of confidence. Conclusion: The inferior pedicle breast reduction technique can be the standard treatment for gestational gigantomastia with the length from suprasternal notch to the nipple $\leq 50 \mathrm{~cm}$ that present without any anatomical complications.
\end{abstract}




\section{Keywords}

Gestational Gigantomastia, Hormones, Surgical, Inferior Pedicle, Medical Treatment

\section{Introduction}

Gigantomastia is a rare disease condition of the breast [1] where the breast undergoes excessive enlargement (hyperplasia). Till date, there is no approved definition for gigantomastia [2] [3] [4] but most authors have described it as a hypertrophic breast condition in which at least $1.5 \mathrm{~kg}$ is resected from each breast during operation [5]. Recently, Dancey et al. proposed gigantomastia as excess breast tissue that contributes greater than $3 \%$ of patient's total body weight. The disease is termed juvenile gigantomastia in teenagers, idiopathic gigantomastia in adults without any known cause and gestational gigantomastia or pregnancy induced gigantomastia in pregnant women with the disease condition [2].

Gestational gigantomastia amongst the different types of gigantomastia cases is the least reported (2). Gestational gigantomastia is very rare in women with an incidence rate of 1 in 100,000 pregnancies [6] [2]. The disease condition has mostly been recorded in Whites, obese and multiparous women [7]; however there have been few cases recorded in Blacks [3] [8]-[17].

Complete mastectomy has been the recommended treatment for gigantomastia [2] [18] due to the ability of the condition to recur even after breast reduction. However, the problem of inability to breast feed among pregnant women taking this treatment is very important, especially in developing countries where breast feeding is very common [3] and most people cannot afford baby formula foods.

The breast reduction technique, though not the ideal for recurring gigantomastia, is recommended for non-recurring cases [19]. The inferior pedicle technique is among the four pedicle breast reduction techniques [4]. Also known as the Wise pattern technique, this technique is highly recommended by most authors for breast reduction because it gives the best post-operative results [20] especially for women in their reproductive age. The technique also gives a very good nipple areolar sensation, breast mound and reduced scar appearance.

In Ghana, gigantomastia cases have been recorded by Agbenorku et al. in a number of publications [9]-[17]. However, no case report of gestational gigantomastia has been addressed singly. After several years in breast surgery, we present a case report on one of our successful breast reductions using the inferior pedicle technique for a gigantomastia patient.

\section{Methodology}

We searched literature using PubMed search engine, Google scholar and the en- 
tire web for published papers on the subject Gestational gigantomastia with keywords; Gestational gigantomastia, breast reduction, pedicle method and inferior pedicle method. In all, thirty-one (31) papers were obtained (Figure 1).

The inferior pedicle breast reduction technique as described by Wallace et al. [21] was employed without any modification in the laid down procedure to treat our patient's bilateral gestational gigantomastia.

\section{Ethical Clearance}

Ethical approval for the study was granted by the Committee on Human Research, Publications and Ethics of the School of Medical Sciences, Kwame Nkrumah University of Science and Technology and the Komfo Anokye Teaching Hospital.

\section{Patient Consent}

Patient consent was sort before using data.

\section{Case Presentation}

A 46-year-old gravida IV quadripara presented to our centre with complains of severe back pains, excruciating pain in both breasts and ribs and inability to undertake hitherto normal daily activities. She exhibited no signs of apparent systemic disease. Upon physical examination she was diagnosed with breast hypertrophy with grade IV ptosis. In the standing position, both breasts extended

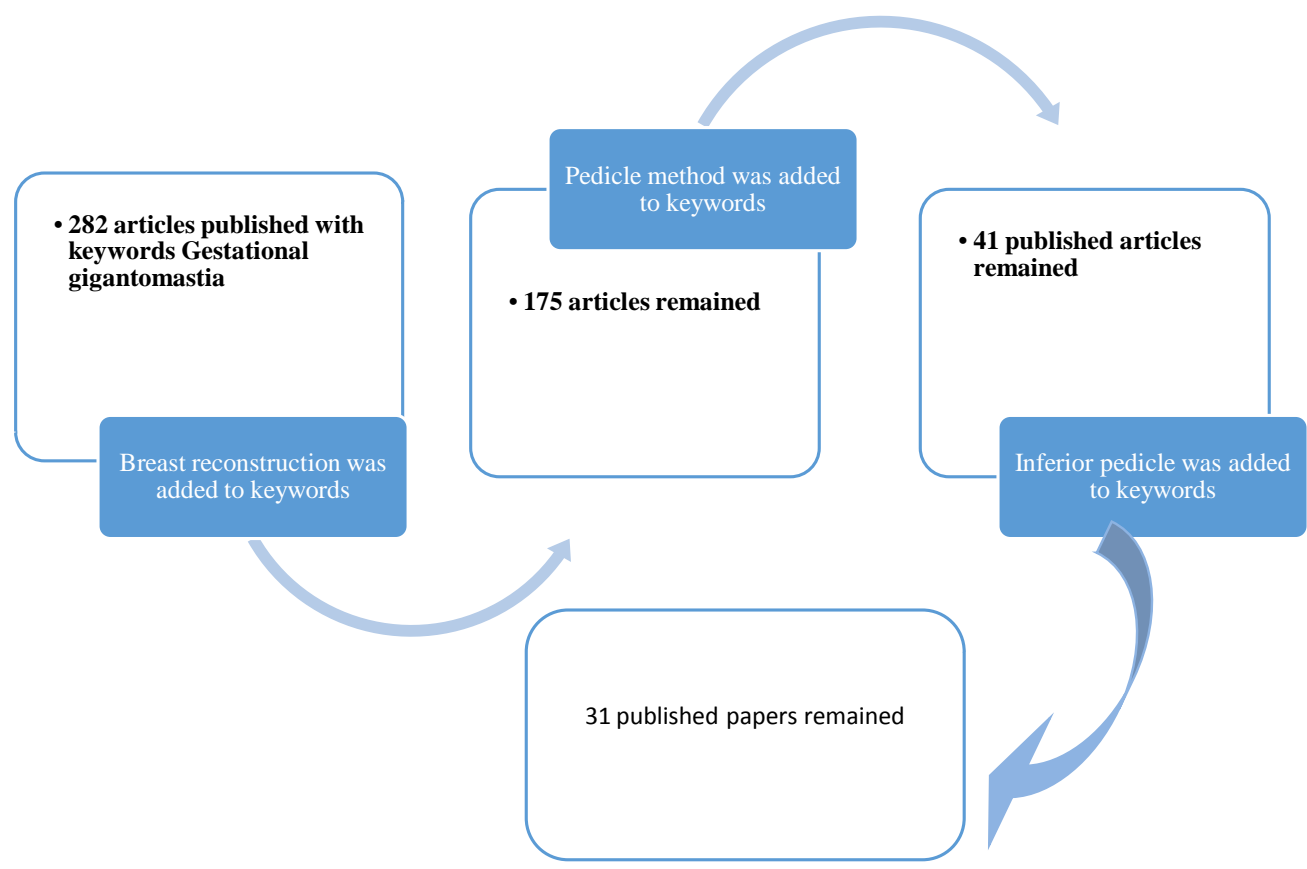

Figure 1. Flow chart of methodology (We searched literature using PubMed search engine, Google scholar and the entire web for published papers on the subject Gestational gigantomastia with keywords; Gestational gigantomastia, breast reduction, pedicle method and inferior pedicle method. In all, thirty-one (31) papers were obtained). 
down to just above her navel with an extended nipple areolar complex (NAC) (Figures 2(a)-(c)). Distance from suprasternal notch to the nipple was $46 \mathrm{~cm}$ and $45 \mathrm{~cm}$ for the right and left breasts respectively.

Further examination revealed she was obese (BMI-32.5). All vital signs and hormonal levels were normal. A mammogram revealed that she had bilateral megalomastia with no evidence of malignancy. The cutis, sub cutis and areolar areas of both breasts were of normal appearance. Additionally, there was no evidence of architectural distortion, normal appearance of both breasts (except the enlarged mounds) and no evidence of enlarged axillary lymph nodes. Breast ultrasonography revealed a fibroglandular pattern with no evidence of focal lesions with normal axillary tail and no evidence of lymphadenopathy.

Other laboratory tests such as the liver and renal function tests, hormonal tests including prolactin indicated normal levels. Prolactin: $25 \mathrm{ng} / \mathrm{dL}$ (normal: 5 to $40 \mathrm{ng} / \mathrm{dL}$ ), Oestradiol: $53 \mathrm{pg} / \mathrm{ml}$ (normal: 25 to $75 \mathrm{pg} / \mathrm{ml}$ ), Progesterone: 16 $\mathrm{ng} / \mathrm{mL}$ (normal: 5 to $20 \mathrm{ng} / \mathrm{mL}$ ), Luteinizing hormone: $9 \mathrm{IU} / \mathrm{L}$ (normal: 0.5 to $16.9 \mathrm{IU} / \mathrm{L}$ ) and Follicle-stimulating hormone: $18 \mathrm{mIU} / \mathrm{ml}$ (normal: 4.7 to 21.5 $\mathrm{mIU} / \mathrm{ml})$.

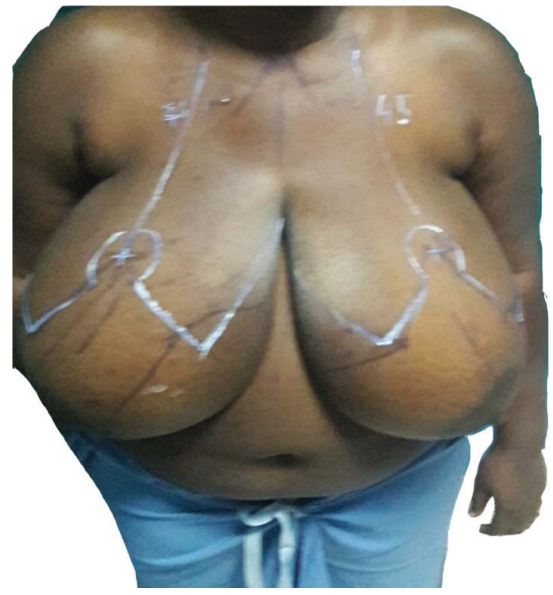

(a)

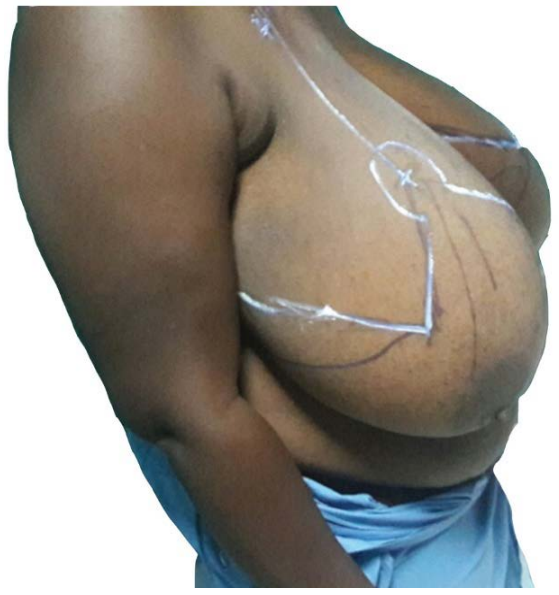

(b)

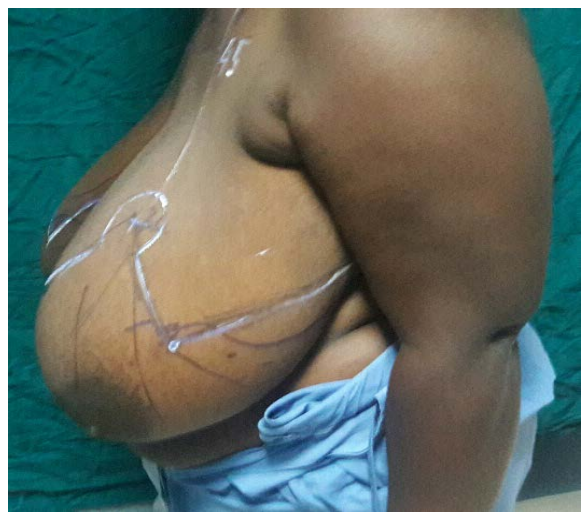

(c)

Figure 2. (a): Anterior view of the breast in a standing position; (b): Right lateral view of the breast; (c): Left lateral view of breast. 


\section{History}

She started experiencing breast enlargement in both breasts during her first conception and only experienced slight breast reduction after breast feeding. The breast remained somewhat dormant till it begun enlarging again during her second conception. There was however no significant breast reduction after the second delivery. She had similar experiences in the latter two conceptions which resulted in breast sizes five times bigger than it was before her first conception. She had normal delivery in all her births; there was no record of ulceration or discharge from both breasts. However, she experienced rashes, itchiness on and around the breasts and excessive pains in her back, shoulders, ribs and both breasts.

After thorough discussion of the alternatives, benefits and risks of the different treatment methods with the patient, breast reduction was the preferred treatment. Breast reduction was therefore performed for her (Figure 3(a), Figure $3(b))$.

This was done after she was prepared adequately, thus put on diet for weight management (immediate weight before surgery: $113 \mathrm{~kg}$ ) and taken through series of comprehensive counselling sessions. The inferior pedicle technique was employed for the breast reduction (Figure 3(a), Figure 3(b)). The base of her breast was $12 \mathrm{~cm}$ wide each. No modification of the inferior pedicle technique was made. A total of $5.8 \mathrm{~kg}$ breast was resected; $3.0 \mathrm{~kg}$ from the right breast and $2.8 \mathrm{~kg}$ from the left breast. After Histopathology of the breast biopsy, there was

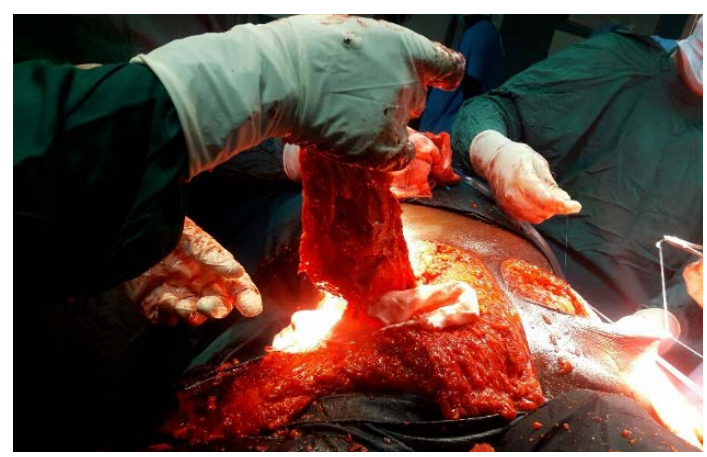

(a)

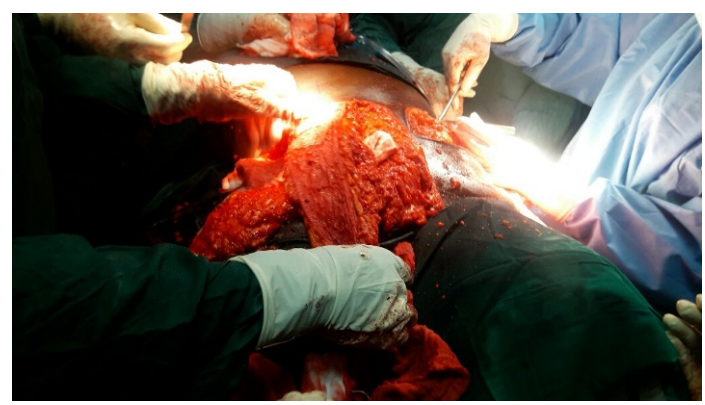

(b)

Figure 3. (a): Intra operative procedure (Inferior pedicle); (b): Intra operative procedure. 
no significant findings, thus, no malignancy. Gestational gigantomastia may resolve to some degree after delivery. However, in this patient, her gigantomastia persisted after her fourth pregnancy. Her symptoms gradually worsened over 12 years to the point that she requested surgical treatment. It is estimated that her breasts, at the time of surgery, were approximately the same size as her breasts at the end of her pregnancy.

At one month post-operation she was greatly satisfied with her new breast size and mound; she also liked the aesthetics (Figures 4(a)-(c)).

At 4 and 7 months post-operation she affirmed that she now experiences with time greater NAC sensation (Figures 5(a)-(c), Figures 6(a)-(c)).

She is satisfied with the breast mounds; with their typical aesthetic adolescent characteristics.

\section{Discussion}

Studies on Gestational gigantomastia, though a rare disease condition is very necessary since its cause is yet not known neither its future prospects.

Our patient's condition was one without any complications and normal hormonal levels similar to other cases reported [22] [23] [3]. On the other hand, several authors have reported Gestational gigantomastia cases with several complications [8]; hypercalcemia [1], hyperprolactemia, hyperoestradiolemia and

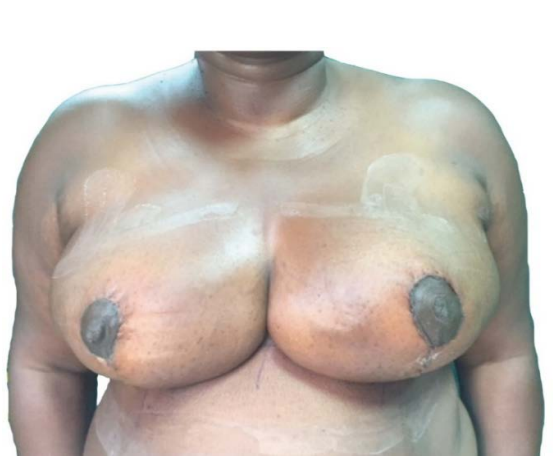

(a)

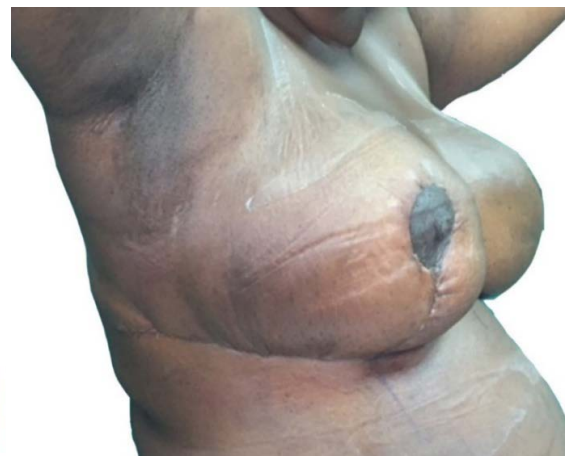

(b)

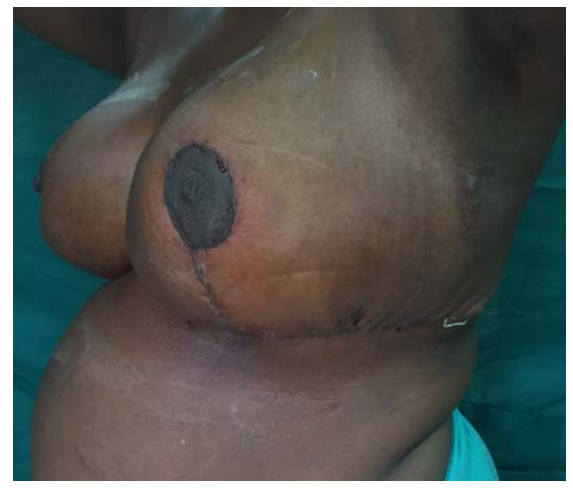

(c)

Figure 4. (a): Anterior view of breasts one month post-OP; (b): Right lateral view of breasts one month post-OP; (c): Left lateral view of breasts one month post-OP. 


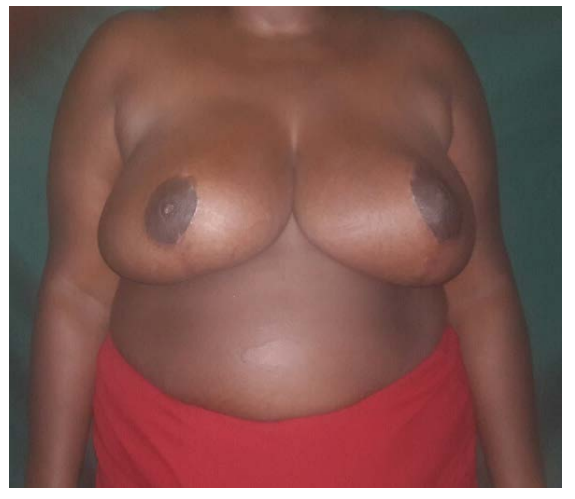

(a)

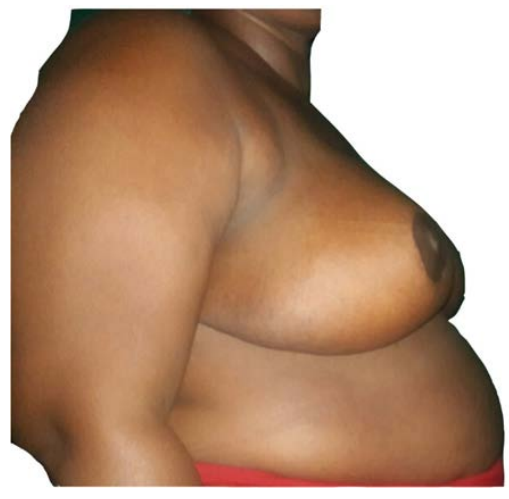

(b)

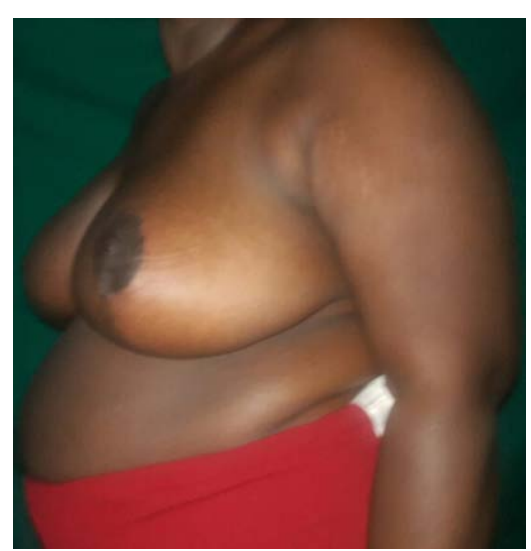

(c)

Figure 5. (a): Anterior view of breasts four months post-OP; (b): Right lateral view of breasts four months post-OP; (c): Left lateral view of breasts four months post-OP.

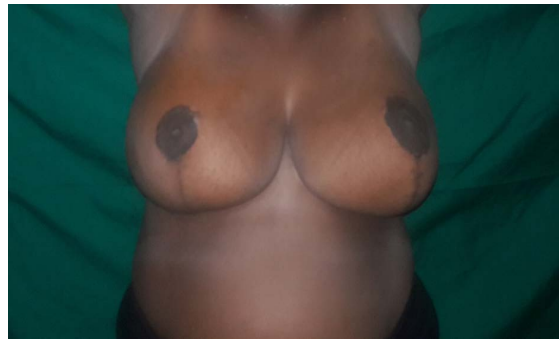

(a)

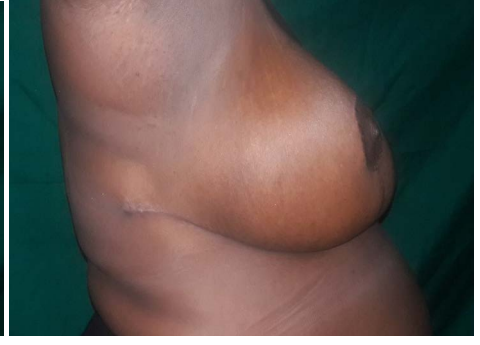

(b)

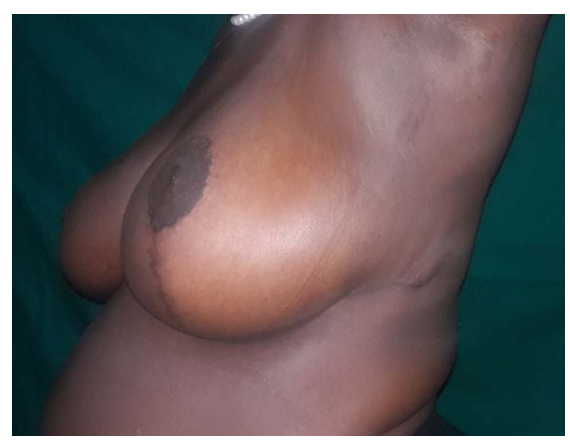

(c)

Figure 6. (a): Anterior view of breasts seven months post-OP; (b): Right lateral view of breasts seven months post-OP; (c): Left lateral view of breasts seven months post-OP. 
lumps in breast [18] [8]. In cases of hormonal complications, clinical measures such as administering drugs like bromocriptine to bring figures to normal have been resorted to. Other complications include breast ulceration and bacterial infection [3] [24]. Wounds are dressed regularly in these cases and potent antibiotics are administered after susceptibility test.

Moschella et al. explained that once pregnancy induced mammary hypertrophy has occurred, further recurrence is likely in subsequent pregnancies [19]. Like a number of others described in literature [25], our patient reported recurring Gestational gigantomastia. The cause of this trend is still not known. However, a few authors have suggested over sensitivity of receptors, hormonal disorders, drugs and autoimmunity. The hormone prolactin is the main hormone suggested to be associated with this disease condition. Our patient presented her case 12 years after her last delivery and recorded normal hormonal levels at the time of the presentation. We can therefore not tell whether the gigantomastia was due to increased hormonal level or not, since she presented years after the incidence when breast enlargement had ceased and probably hormonal levels had dropped to normal. However, some Gestational gigantomastia patients have responded well to high doses of anti-hormonal agents such as bromocriptine, medroxyprogesterone, tamoxifen and danazole [8] [22].

Despite the few case resolutions of Gestational gigantomastia after anti-hormonal therapy [8] [22], the case is dicey, whether the case resolved was due to the drug therapy or not, since Begum et al.'s patient, unlike Troare et al.'s, had normal hormonal levels. Moreover in some patients the disease persisted even after the drug therapy [1] [24] [26], while in others the disease resolved by itself without any medications [3]. Nevertheless, it is recommended that anti-hormonal drugs are administered to Gestational gigantomastia patients as first line treatment but with much caution not to interfere with the unborn baby [25] [27]. Some of these drugs have negative side effects to the patient: medroxyprogesterone has been associated with amenorrhoea and formation of benign mammary nodules [2]. After thorough explanation of the prospects of the anti-hormonal therapy and surgical treatment, our patient opted for surgery; not mastectomy, but breast reduction.

So far, the ideal treatment for the disease condition is surgery [1] [20] [27]. A number of techniques have been developed and are being improved upon for better results; complete mastectomy and breast reduction; using the four major pedicle methods or their modifications.

The pedicle technique for Gestational gigantomastia breast reduction has been recommended by several authors [20]. Amongst these techniques, the inferior and superior pedicle methods have been used the most with varying outcomes. However, it has been reported that the superior pedicle technique is mostly associated with NAC sensation reduction [28]. Moschella et al. have stated that the success of the Gestational gigantomastia breast reduction does not solely depend on the technique used but also the experience of the surgeon with the technique, 
how comfortable the surgeon is with the technique and the size of the breast [19]. That notwithstanding, most surgeons prefer the inferior pedicle technique to the other techniques [9] [2]. Chopra et al. have added that the frequent use of the technique is because it can be used on any length breast and it is not constrained by measurement [29]. Lacerna et al. shared their success in the use of the inferior pedicle technique for 219 breast reductions for gigantomastia without any of the cases requiring nipple grafting [20]. DeGeorge et al. also upon their many years of breast reduction have recommended the Wise pattern for breast reduction [30]. We do acknowledge that some authors have recommended specific techniques for different presentations of gigantomastia [4] [19]. However, we are of the view that the inferior pedicle technique can be used for the different forms of gestational gigantomastia cases without any major anatomical complications. This is because to the surgeon, it offers versatility and wide access to dermal parenchyma with the inverted $\mathrm{T}$ incision making the technique very effective for a large variety of reduction sizes, especially high-volume reductions. To the patient, the technique gives excellent results especially for elevation of the NAC, preserving lactation and NAC sensation; these according to Moschella et al. are the factors that usually determine the choice of pedicle [19] and excellent blood circulation.

We agree with Kling et al. that the choice of technique should depend on operator experience and comfort level with procedure [4]. For that reason we would recommend that surgeons who are not yet using the technique learn and adopt it for excellent results. However, if after discussing all the breast reduction methods and patient has her own preference over what the surgeon is comfortable with, surgeons should stick to patient's preference. The patient's goal is very important in breast reduction [4].

The complication mostly associated with the inferior pedicle method is the widening of the inferior portion of the inverted $\mathrm{T}$ incision, $7 \%$ to $20 \%$ of the time [4] [20]. Fortunately, this complication was not observed in our patient. Our patient has been very satisfied on the whole.

\section{Conclusion}

Majority of surgeons have resorted to the use of inferior pedicle breast reduction technique as surgical treatment for gigantomastia with very positive outcomes. This proves that the method is very good and can be the standard treatment for all gestational gigantomastia cases with the length from suprasternal notch to the nipple $\leq 50 \mathrm{~cm}$, which present without any anatomical complications.

\section{Conflict of Interest}

The authors declare no conflict of interest.

\section{Acknowledgements}

The authors sincerely thank Miss Angelina Effah, Biostatistician and Research 
Officer of PIMA Hospital-Kumasi and Mr. Abdul-Rahman Adamu Bukari of the University of Bath, UK, for diligently editing this manuscript.

\section{References}

[1] Shoma, A., Elbassiony, L., Amin, M., Zalata, K., Megahed, N., Elkhiary, M. and Abdelaal, I. (2011) “Gestational Gigantomastia”: A Review Article and Case Presentation of a New Surgical Management Option. Surgical Innovation, 18, 94-101. https://doi.org/10.1177/1553350610391106

[2] Dancey, A., Khan, M., Dawson, J. and Peart, F. (2008) Gigantomastia-A Classification and Review of the Literature. Journal of Plastic, Reconstructive \& Aesthetic Surgery, 61, 493-502. https://doi.org/10.1016/j.bjps.2007.10.041

[3] Ezem, B.U., Osuagwu, C.C. and Opara, K.A. (2011) Gestational Gigantomastia with Complete Resolution in a Nigerian Woman. BMJ Case Reports, 2011, bcr0120102632. https://doi.org/10.1136/bcr.01.2010.2632

[4] Kling, R.E., Tobler, W.D., Gusenoff, J.A. and Rubin, J.P. (2016) Avoiding Complications in Gigantomastia. Clinics in Plastic Surgery, 43, 429-439.

https://doi.org/10.1016/j.cps.2015.12.006

[5] Dafydd, H., Roehl, K.R., Phillips, L.G., Dancey, A., Peart, F. and Shokrollahi, K. (2011) Redefining Gigantomastia. Journal of Plastic, Reconstructive \& Aesthetic Surgery, 64, 160-163. https://doi.org/10.1016/j.bjps.2010.04.043

[6] Agarwal, N., Kriplani, A., Gupta, A. and Bhatla, N. (2002) Management of Gigantomastia Complicating Pregnancy. A Case Report. The Journal of Reproductive Medicine, 47, 871-874.

[7] Resende, J.H.C., di Carlantônio, L.F.M., Freitas, L.C.M., Tonini, T., de Figueiredo, N.M.A. and Santiago, L.C. (2015) Operative Technique for Correction of Gigantomastia, using the Superior Pedicle, with Special Care for the Nipple-Papillary Grafts: A 13-Year Retrospective Study. Modern Plastic Surgery, 5, 34. https://doi.org/10.4236/mps.2015.53007

[8] Traoré, B., Kamate, B., Conde, M., Keita, A.M., Kourouma, T. and Dem, A. (2015) An Exceptional Case of Bilateral Gestational Gigantomastia with Multiple Breast Lumps. The Pan African Medical Journal, 20. https://doi.org/10.11604/pamj.2015.20.309.6544

[9] Agbenorku, P. and Addae-Mensah, L. (2001) Management of Juvenile Macromastia: Our Experience at the KomfoAnokye Teaching Hospital (KATH), Kumasi, Ghana. Indian Journal of Clinical Practice, 2, 13-16.

[10] Agbenorku, P. (2007) Breast Diseases including Breast Developmental Anomalies in Kumasi, Ghana. NJPS, 3, 11. https://doi.org/10.4314/njpsur.v3i1.40386

[11] Agbenorku, P., Agbenorku, M., Iddi, A., Amevor, E., Sepenu, R., Osei, D. and Kyei, I. (2010) Incidence of Breast Developmental Anomalies: A Study at Sogakope, Ghana. Nigerian Journal of Plastic Surgery, 6, 1-5. https://doi.org/10.4314/njpsur.v6i1.53586

[12] Agbenorku, P., Agbenorku, M., Iddi, A., Amevor, E., Kofitse, M. and Klutsey, E. (2011) Awareness of Breast Developmental Anomalies: A Study in Jamasi, Ghana. Aesthetic Plastic Surgery, 35, 745-749. https://doi.org/10.1007/s00266-011-9680-5

[13] Agbenorku, P., Agamah, G., Agbenorku, M. and Obeng, M. (2012) Reduction Mammaplasty in a Developing Country: A Guideline for Plastic Surgeons for Patient Selection. Aesthetic Plastic Surgery, 36, 91-96. https://doi.org/10.1007/s00266-011-9750-8 
[14] Agbenorku, P. (2012) Breast Developmental Anomalies: A Review of the Problem.

[15] Agbenorku, P., Otupiri, E. and Fugar, S. (2013) Breast Developmental Anomalies in Dormaa Municipality of Ghana: Prevalence and Impact on the Life of the Individual. Plastic Surgery International. https://doi.org/10.1155/2013/140704

[16] Agbenorku, P. (2013) A Long Term Review of Surgically Treated Enlarged Breasts. Modern Plastic Surgery, 3, 113. https://doi.org/10.4236/mps.2013.34023

[17] Agbenorku, P. and Agbenorku, M.A. (2013) 16-Year Follow-Up on a Juvenile Macromastic Patient. Journal of Medicine and Medical Sciences, 4, 382-386.

[18] Türkan, H., Gökgöz, M.Ş., Taşdelen, İ. and Dündar, H.Z. (2016) Gestational Gigantomastia. Journal of Breast Health, 12. https://doi.org/10.5152/tjbh.2016.2852

[19] Moschella, F., Cordova, A. and Toia, F. (2016) Gigantomastia. International Textbook of Aesthetic Surgery. Springer, Berlin Heidelberg, 239-245.

https://doi.org/10.1007/978-3-662-46599-8_18

[20] Lacerna, M., Spears, J., Mitra, A., Medina, C., McCampbell, E. and Kiran, R. (2005) Avoiding Free Nipple Grafts during Reduction Mammaplasty in Patients with Gigantomastia. Annals of Plastic Surgery, 55, 21-24. https://doi.org/10.1097/01.sap.0000168249.09491.21

[21] Wallace, W.H., Thompson, W.O.B., Smith, R.A., Barraza, K.R., Davidson, S.F. and Thompson, J.T. (1998) Annals of Plastic Surgery.

[22] Begum, A., Iqbal, K. and Kyani, K. (2015) A Rare Case of Recurrent Gestational Gigantomastia with Complete Resolution after Delivery. Journal of Society of Obstetricians \& Gynaecologists of Pakistan, 5, 51-54.

[23] Rezai, S., Nakagawa, J.T., Tedesco, J., Chadee, A., Gottimukkala, S., Mercado, R. and Henderson, C.E. (2015) Gestational Gigantomastia Complicating Pregnancy: A Case Report and Review of the Literature. Case Reports in Obstetrics and Gynecology. https://doi.org/10.1155/2015/892369

[24] Eler dos Reis, P., Blunck Santos, N.Q., Barbosa Pagio, F.A., Chambô, F., Chambô, D. and ChambôFilho, A. (2014) Management and Follow-Up of a Case of Gestational Gigantomastia in a Brazilian Hospital. Case Reports in Obstetrics and Gynecology. https://doi.org/10.1155/2014/610363

[25] Antevski, B.M., Smilevski, D.A., Stojovski, M.Z., Filipovski, V.A. and Banev, S.G. (2007) Extreme Gigantomastia in Pregnancy: Case Report and Review of Literature. Archives of Gynecology and Obstetrics, 275, 149-153. https://doi.org/10.1007/s00404-006-0190-7

[26] Alotaibi, F. (2016) Gestational Gigantomastia: A Case Report. Journal of Case Reports and Images in Surgery, 2, 97-100.

[27] Swelstad, M.R., Swelstad, B.B., Rao, V.K. and Gutowski, K.A. (2006) Management of Gestational Gigantomastia. Plastic and Reconstructive Surgery, 118, 840-848. https://doi.org/10.1097/01.prs.0000232364.40958.47

[28] Schlenz, I., Rigel, S., Schemper, M. and Kuzbari, R. (2005) Alteration of Nipple and Areola Sensitivity by Reduction Mammaplasty: A Prospective Comparison of Five Techniques. Plastic and Reconstructive Surgery, 115, 743-751. https://doi.org/10.1097/01.PRS.0000152435.03538.43

[29] Chopra, K., Tadisina, K.K. and Singh, D.P. (2013) Breast Reduction Mammaplasty. Eplasty 13.

[30] DeGeorge, B.R., Colen, D.L., Mericli, A.F. and Drake, D.B. (2013) Reduction Mammoplasty Operative Techniques for Improved Outcomes in the Treatment of Gigantomastia. Eplasty 13. 